\title{
LOS ALEMANES COMO PERSONAJES LITERARIOS EN LA LITERATURA COLOMBIANA CONTEMPORÁNEA ${ }^{1}$
}

\author{
VOLKER JAECKEL \\ Universidade Federal de Minas Gerais \\ Belo Horizonte \\ volkerjae@yahoo.de \\ ORCID: 0000-0002-0345-8493
}

\section{RESUMEN}

El presente trabajo analiza la imagen del alemán en la literatura colombiana desde los años 70 hasta hoy. A pesar de que desde el siglo XVI los alemanes tuvieran un papel importante en la colonización del Reino de la Nueva Granada, se puede detectar una mayor presencia con un papel más decisivo en novelas que abarcan los siglos XIX y especialmente el siglo XX. Se trata principalmente de soldados, exiliados, judíos, emigrantes y nazis de origen germano, quienes dejaron sus huellas en la literatura del país latinoamericano. Para llevar a cabo el análisis vamos a presentar y comentar cinco novelas escritas en los últimos 40 años con un enfoque en personajes de origen alemán o donde los alemanes son figuras literarias que tienen una influencia sobre el desarrollo de la narración. Serán tratados tanto textos con personajes históricos como aquellos con personajes de ficción.

PALABRAS CLAVE: historia de Colombia, literatura contemporánea, alemanes como personajes literarios.

\section{GERMANS AS LITERARY FIGURES IN CONTEMPORARY COLOMBIAN NOVELS}

\section{ABSTRACT}

This paper will analyze the image of Germans in Colombian literature from the 1970s to the present day. Although the Germans played an important role in the colonization of the Kingdom of New Granada since the $16^{\text {th }}$ century, we detected a greater presence of this figures with a more decisive role in the novels, in the $19^{\text {th }}$ and especially the $20^{\text {th }}$ centuries. Mainly soldiers, exiles, Jews, emigrants and Nazis of German origin left their traces in the literature of the Latin American country. To carry out the analysis we will present and comment on five novels written in the last 40 years focusing on characters of German origin or where Germans as literary figures have an influence on the development of the narrative. Both texts with historical characters and those with fictional characters will be treated.

KEYWORDS: Colombian history, contemporary literature, Germans as literary figures.

1 El presente artículo fue concluido durante una estadía de investigación en la Europa Universität Flensburg (EUF), Alemania, financiado por el Servicio Alemán Académico (DAAD) en junio de 2019. 


\section{LOS ALEMANES EN LA HISTORIA DE COLOMBIA}

En el siglo XVI ya se tuvo noticia de la llegada de alemanes a Colombia con la intención de participar en la colonización y lucrarse con la conquista de las Américas. Ejemplo de ellos son Los Welser, familia de banqueros con sede en Augsburgo, quienes enviaron emisarios para cumplir esta tarea.

Nicolás de Federmann y Ambrosio Alfinger son dos de los nombres más importantes de aquella época. El primero era un militar y mercader, nacido en Ulm en 1505, enviado a Sevilla para gerenciar una factoría y en 1529 a Santo Domingo. Más tarde llegó a la recién creada provincia de Venezuela, producto de un acuerdo entre Carlos I de España y los banqueros Welser, que daría pasó a la creación del Klein-Venedig o Welserland (Pequeña Venecia o País de los Welser) (como se le conocía en Alemania en esa época), siendo los primeros europeos no latinos sino germánicos que iniciaron el proceso colonizador en América.

Federman partió en busca del legendario El Dorado y emprendió las más arriesgadas travesías hacia el interior del país, impulsado por una ambición devoradora.

El conquistador germano colaboró decisivamente en la fundación de Bogotá y también en la creación del Nuevo Reino de Granada. Contribuyó no solo a poblar Bogotá, sino también a Vélez y a Tunja. Descendientes de sus conquistas son seguramente algunos «indios rubios» de Boyacá.

Ambrosio Alfinger, sucesor de Federmann en la gobernación de Venezuela, era también agente de los Fugger y partió como Federmann de la ciudad Coro en Venezuela.

En el siglo XIX cabe mencionar los proyectos de colonización realizados en varias ciudades de Santander, liderados por el ingeniero y terrateniente alemán Geo von Lengerke. Llegó a Colombia hacia 1852, huyendo de la justicia por causa de un duelo. Se instaló en el entonces Estado Soberano de Santander, donde se dedicó a la exportación e importación de mercancías, a la explotación y el comercio de la quina, a la construcción de caminos y a la colonización de tierras en el valle del río Magdalena, llegando a poseer más de 12.000 hectáreas. Entre sus haciendas, las más famosas fueron «El Corregidor» ubicada en el Municipio de Girón, «Montebello» y «El Florito», ubicadas en el actual Municipio de Betulia, en las cuales vivió en medio de extravagancias. Se hizo famoso por sus hazañas con muchas mujeres y su innumerable descendencia con huellas permanentes hasta hoy en la región, donde se encuentran hombres y mujeres altos con ojos azules.

En el siglo xx destacan las actividades económicas de los alemanes en Barranquilla, ya que ellos fueron considerados elementos dinamizadores del desarrollo de la ciudad, especialmente después de la Primera Guerra Mundial y durante los años 30 del siglo pasado. Se trata de una de las colonias de extranjeros más influyentes de la zona. En aquella época Barranquilla se 
transformó en el primer puerto del país, que conectaba Colombia con el resto del mundo por el mar, el río Magdalena y el transporte aéreo. Ya en el año 1854 hubo un tratado firmado entre las ciudades de Bremen, Hamburgo y Lübeck y Nueva Granada sobre «Amistad, comercio y navegación».

Desde los años 70 del siglo XIX se inició la construcción de un ferrocarril, por la firma alemana Hoenisberg, Wessel \& cia. Más tarde se instalaron otras casas comerciales provenientes de Hamburgo y Bremen en la ciudad. Con el crecimiento de la colonia alemana fueron fundados en 1904 el club alemán y en 1912 el primer colegio alemán en Colombia, seguido de los de Bogotá (1922) y Cali (1935) (Lázaro 2012: 169).

Durante la República de Weimar, Suramérica fue el destino predilecto de muchos alemanes decididos a probar suerte lejos de su tierra natal. Llegaron a Barranquilla motivados por el éxito de sus compatriotas. Hubo un considerable número de empresas de navegación fluvial, como la Empresa de Vapores Lindemeyer, clasificada como la cuarta más grande entre las 23 compañías. En 1935 Barranquilla tenía más de 150.000 habitantes y la población seguía creciendo en más de 2000 habitantes por año. Los alemanes trabajaron en el sector inmobiliario comprando y vendiendo casas y terrenos en grande estilo. En los años 1930 y 1931 se registraron numerosas compras de terrenos y una importante participación en la comercialización, así como en proyectos de urbanización de la ciudad.

Entre los logros más importantes de los alemanes en Colombia debe ser mencionado la fundación de la Sociedad Colombo-Alemana de Transportes Aéreos (SCADTA). En este mismo año llegó a Barranquilla el señor Werner Kämmerer, un agente viajero alemán, que llevaba a Colombia una fábrica de aviones de guerra ya transformada para el uso comercial. Se puso en contacto con sus compatriotas residentes en Bogotá y Barranquilla, donde fundó en 5 de diciembre de 1919 junto con Alberto Tietjen, Ernesto Cortissoz, Rafael María Palacios, Cristóbal Restrepo y Stuart Hocie la segunda compañía aérea más antigua del mundo, que aún hoy existe (después de la KLM). El primer viaje se realizó bajo el comando del alemán von Krohn el día 12 de octubre de 1920 entre Barranquilla y Girardot. Hasta 1940 la empresa operó con este nombre hasta transformarse en Avianca, cuando fueron despedidos los 80 empleados alemanes. Hoy es la segunda línea aérea del continente suramericano.

La navegación tanto por mar y río como por aire fue una de las actividades más representativas de las que desarrollaron los alemanes en Barranquilla. Ellos participaron en el proceso de conexión entre los distintos puntos del país y con el exterior y prestaron servicios durante la guerra con el Perú en 1932, a través del trazado de las fronteras colombianas por medio de los aviones de la SCADTA.

También hubo una actuación considerable de las casas comerciales dirigidas por alemanes, entre los cuales se pueden identificar dos tipos según su capacidad operativa: mayores y menores (Lázaro 2012: 184). La predominancia 
en estas actividades abrió las puertas a los alemanes para su inserción en la sociedad nativa. Muchos de ellos se emplearon en otras actividades como la de la representación y la producción de productos agroquímicos o farmacéuticos o en la fabricación de cerveza.

La Segunda Guerra Mundial condujo a la última etapa de la influencia alemana en Barranquilla como en toda Colombia. Al final de los años treinta la influencia de los alemanes era notable, ya que no pocos inmigrantes se habían hecho prósperos empresarios, pero en poco tiempo sería alterado por la política internacional y las consecuencias del conflicto de la Segunda Guerra Mundial. Ciudadanos de los países del eje como italianos, japoneses y alemanes padecieron los rigores de la presión de los Estados Unidos sobre el gobierno colombiano. A mediados de 1941 fueron publicadas las Listas Negras: ${ }^{2}$

documentos emitidos por el gobierno norteamericano y que eran enviados a las autoridades y difundidos en diarios de circulación nacional y local, en los que aparecían los nombres de empresas y personas naturales a los que se acusaba de simpatía y/o colaboración con los totalitarismos en conflicto con los Aliados [...]. (Lázaro 2012: 190)

Como consecuencia de la publicación de las Listas Negras y de la presión ejercida sobre los ciudadanos del Eje se produce una ruptura en la influencia de los alemanes en Colombia. Una buena cantidad de alemanes tuvieron que salir del país en barcos a Estados Unidos y desde allí a Europa. Está comprobado que hubo traspaso de bienes de alemanes a ciudadanos colombianos confiando en una posterior devolución. En el año 1938 hubo un crecimiento del número de alemanes y austriacos que emigraron de sus países de origen hacia Colombia. En las Listas Negras fueron citados 385 personas en Bogotá y 217 en Barranquilla.

Los norteamericanos justificaban sus acciones con el temor a una situación provocada por la guerra. A lo largo del continente sudamericano se habían formado puntos de apoyo al nacionalsocialismo, que estaban formados por alemanes que tenían su residencia principalmente en Brasil, Chile y Argentina. Colombia no fue una excepción y en Barranquilla hubo manifestaciones de abierta adhesión al nazismo.

A lo largo del continente, se formaron núcleos de apoyo al nacionalsocialismo que estaban integrados por no pocos alemanes que tenían su residencia permanente en cada país. Tal vez los casos más conocidos son los de Brasil, Argentina y Chile, pero Colombia no fue la excepción y precisamente en Barranquilla desarrollaba sus actividades un

${ }^{2}$ Durante la Segunda Guerra Mundial, las llamadas Listas Negras del Departamento de Estado de los Estados Unidos tuvieron como objeto bloquear los fondos del Eje en Latinoamérica. Especialmente en Colombia, ese sistema sirvió para abusos contra personas que no eran nazis. Las consecuencias eran confiscaciones, deportaciones, internamientos y otras acciones punitivas. La primera versión de las Listas Negras es de julio de 1941. Ya antes de la entrada en la guerra, los Estados Unidos querían ganar el dominio económico en la América Latina frente a la Alemania Nazi (véase Cardona González 2018: 103 y 165ss.). 
"Stützpunkt" o "Punto de Apoyo" que llevaba a cabo manifestaciones de abierta adhesión al nazismo. El temor frente a posibles actividades de proselitismo político y espionaje o incluso el riesgo de ataques sobre un espacio vital como lo era el Canal de Panamá, fueron argumentos para buscar neutralizar a los alemanes en la ciudad. (Lázaro 2012: 193$)^{3}$

Los Estados Unidos consideraron la actuación de los alemanes como una forma de injerencia de una potencia extranjera en una zona considerada de influencia norteamericana.

Varios de los libros aquí analizados hacen referencia a la época y a los acontecimientos en torno a las Listas Negras y también a las actividades económicas de alemanes en los años 30 y 40 en Barranquilla y otras ciudades del Caribe como Cartagena.

No podemos olvidar que hubo tres ondas de emigraciones de ciudadanos de lengua alemana, una en el siglo XIX y después de la Primera Guerra Mundial hasta inicio de los años treinta, formada por personas que buscaron éxito económico y una vida mejor, una otra durante el régimen nazi, formada por emigrantes políticos y judíos sobre todo entre 1938-1941, que intentaron escapar de los campos de concentración y una tercera muy pequeña al final de la Segunda Guerra Mundial formada por criminales nazis fugitivos.

Todas estas ondas migratorias tuvieron una repercusión sobre el país y sobre la figura del alemán en la literatura colombiana. La imagen del alemán en la literatura suramericana ciertamente es dominada por los acontecimientos relacionados con la época del nacionalsocialismo, pero no hay que olvidar su papel importante para el desarrollo del país a lo largo de la historia.

\section{LA OTRA RAYA DEL TIGRE}

Vamos a empezar el pequeño recorrido literario con un libro sobre los alemanes en Colombia en el siglo XIX. Se trata de La otra raya del tigre, publicado por Pedro Gómez Valderrama en 1977.

Geo von Lengerke es un personaje de la vida real, un alemán que llegó a Colombia en 1852 huyendo de la justicia. Se alejaba de las consecuencias de haber ganado un duelo a muerte en su país natal. El personaje histórico tiene el mérito de haber desarrollado una casa de comercio y haber hecho importantes caminos en Santander. Su nombre está grabado en placas conmemorativas y sus genes germanos y pelirrojos están dispersos en no pocas familias santandereanas. Así como Lengerke llegaron otros alemanes, creyendo en la prosperidad económica que Lengerke les había prometido. La novela de Gómez

\footnotetext{
3 Véase también la tesis doctoral de Lázaro (2016), que analiza la presencia alemana en Barranquilla con muchos pormenores y aporta importantes documentaciones a la investigación del tema, aunque enfatiza las actividades económicas, no deja de tener en cuenta las manifestaciones políticas, culturales y sociales de los alemanes.
} 
Valderrama no es estrictamente histórica, pero sin duda tiene la intención de retratar esa época, en la que los liberales santandereanos querían fundar su propio estado, la época de la breve constitución federalista de Rionegro, una época del cultivo de la Quina, una época en la que los indios Yarigues seguían luchando para defender sus tierras ancestrales. Pedro Gómez Valderrama habla en su novela del «reino del caimán», una tierra que hace soñar y que se refiere al Río Grande de la Magdalena. Una gran arteria fluvial que otrora fue abundante en reptiles:

\begin{abstract}
Estamos en el reino del caimán, navegamos en él, el dios caimán nos detiene o nos deja pasar, aquel caimán dormido sobre el cual se ha posado una garza inverosímil podría matarnos a todos si el barco se hunde, si se rompe el casco sobre un banco de arena; el río aquí es ancho, desmesurado, es diez veces el Sena, quince veces el Weser, los castillos que se reflejan en el Rhin son aquí los caimanes taciturnos como fortalezas vigilantes, como hace tres mil años. Cocodrilos, caimanes, castillos, yacarés verdes como la naturaleza, son más imponentes y duros que la cáscara del buque, ésta es la sinfonía del río, es el río-dios que encontraron los conquistadores españoles, cuando entre ellos se mezclaron los primeros aventureros alemanes. (Gómez Valderrama 1986: 15)
\end{abstract}

Ya en el inicio de la novela podemos encontrar en este parágrafo la comparación nostálgica entre Alemania y Colombia, que documenta también la fascinación por la abundancia y por las dimensiones de la naturaleza en el Nuevo Mundo.

Los alemanes santandereanos venían principalmente de Bremen, y el pelirrojo Lengerke de esta novela tal vez compartía con el personaje histórico el anhelo de hacer su pequeño feudo junto a la imponente serranía de los yariguíes en el municipio de Zapatoca. Los alemanes llegaron siguiendo a Lengerke «en su cabalgata de conquistadores pacíficos» (Gómes Valderrama 1986: 58), uno tras otro, y desde San Gil, Zapacota y Bucaramanga pronto lideraron el desarrollo económico de la región.

El olfato de comerciante impulsó a Lengerke a solucionar el transporte del interior hacia los puertos, debido a lo cual dirigió la construcción del camino de Zapatoca a Barrancabermeja, una ruta comercial a favor del desarrollo de Santander que no alcanzó a ver terminada. Precisamente los Yariguíes obstruyeron en aquel momento la construcción por violar sus territorios ancestrales.

El Lengerke de la novela es un hombre que forja caminos, un hombre que hace puentes, cuando hacer un puente sobre un río era una clara expresión de progreso. Su casa de comercio los requería, y más tarde, la explotación de la quina los necesitaba. En el último cuarto del siglo XIX el Gobierno de Colombia concedió la explotación de cultivos de quina a grandes comerciantes, entre los que estaba Lengerke. Lamentablemente, la crisis del mercado de la quina en el exterior y la adicción al brandy del alemán, no solo derrumbaron sus inversiones, sino su salud. Y de esta forma murió, en el relato de Gómez Valderrama. 
Gero von Lengerke es conocido como un hombre mujeriego, al que sucumbían hasta las mujeres casadas, como es mencionado en la novela repetidamente: «Las mujeres lo quieren mucho, porque paga bien a los maridos y es considerado con ellos, y algunas porque las lleva a compartir el lecho o las goza a campo abierto» (Gómez Valderrama 1986: 94).

La novela es la historia de un constante viaje entre el viejo y el nuevo mundo por un lado y de viajes dentro de Colombia, pero los viajes de Lengerke no solamente representan la transición geográfica entre dos continentes, sino un movimiento permanente de pensamiento entre diferentes épocas, entre el tiempo medieval feudal y las tendencias liberales del siglo de la independencia de los estados latinoamericanos. Es la trayectoria de un individuo desgarrado entre continentes y culturas diferentes, una persona sin tierra (cf. Mahlendorf 2000: 209).

Quería y no quería volver. Añoraba la tierra vieja, las forestas educadas y plácidas, los ríos tranquilos, los castillos. Pero esta tierra, en cuya dureza, en cuyos violentos climas, el salvajismo estaba a flor de piel en los ejemplares más cultos de la especia, le atraía con su con su fascinación desmesurada, con sus montañas, con los tajos profundos de sus ríos $[\ldots]$

Nada más atractivo para un alemán civilizado del siglo XIX, que verse hundido hasta el cuello en este mundo en formación, en esta edad media que recreaba todas las fuerzas oscuras y perdidas, las mantenía vivas en su caótica composición social. (Gómez Valderrama 1986: 43)

Lengerke es el prototipo del europeo, cansado de los progresos de la civilización, que encuentra en el continente americano un espacio salvaje, lleno de energía y sin desgastes (cf. Mahlendorf 2000: 209). Al aventurero alemán le fascina el mundo en formación con sus libertades creativas, un mundo primitivo con una composición caótica, que por lo visto necesita la mano organizadora del europeo, según la percepción de Lengerke.

Andrea Mahlendorf interpreta la novela con la intención de crear un nuevo mito y considera a Lengerke como uno de los fundadores («Gründerväter») del moderno estado americano que se transformó en mito, teniendo impacto de esta forma hasta el presente:

En la obra de Valderrama, su proceso de arraigo, su adquisición de identidad espacial y cultural es ejemplar para la búsqueda de la identidad de las naciones latinoamericanas [...] Así, Lengerke, como migrante entre los mundos, es expresión literaria de la búsqueda latinoamericana de la patria, del lugar de llegada y del hogar. ${ }^{4}$

4 «Sein Prozess der Verwurzelung, sein Erwerb räumlicher und kultureller Identität steht bei Valderrama exemplarisch für die Identitätssuche der lateinamerikanischen Nationen [...] So ist Lengerke, als Wanderer zwischen den Welten, literarischer Ausdruck der lateinamerikanischen Suche nach Heimat, dem Ort des Ankommens und Zuhauseseins» (Mahlendorf 2000: 214, traducción nuestra). 
Lengerke representa de cierta forma el sentimiento de estar dividido entre dos continentes, entre dos culturas, la fascinación por la vida en los trópicos y al mismo tiempo el rechazo del nuevo, del inusitado, la añoranza de las raíces, de la tierra de origen y está dominado por el sentimiento de desarraigo.

Hay también varias críticas al libro, que no aceptan la interpretación del papel histórico del alemán, lo encuentran ennoblecido o enaltecido, en lo que se refiere a sus logros y su fracaso identificado con el fracaso del país, y acusan al autor de tener una falta de crítica de la postura imperialista y feudal del conquistador del siglo XIX.

\begin{abstract}
Más que la epopeya de un liberal feudal, el héroe de La otra raya del tigre es símbolo del imperialismo moderno. Por eso la apología resulta falaz y ahistórica. Gómez Valderrama quiere hacernos creer que el fracaso de Lengerke fue nuestro fracaso, que si él hubiese triunfado otro sería nuestro destino. Renovado Sarmiento, Gómez Valderrama no ve, no quiere ver, en las doce mil hectáreas y sus ejércitos para defenderlas, nuestra ruina, el símbolo de nuestros fracasos. Porque hay algo terrible en esta novela: la conciencia que tiene Gómez Valderrama de que Lengerke estaba levantando una nueva nación. ${ }^{5}$
\end{abstract}

El reto de levantar una nueva nación está presente también en otras novelas con personajes alemanes, aunque sean novelas con un claro enfoque en la cuestión de las Listas Negras, del racismo, del antisemitismo y de las persecuciones sufridas durante los años del siglo XX.

\title{
LOS INFORMANTES
}

La novela Los informantes de Juan Gabriel Vásquez fue publicada en 2004 y cuenta una historia muy intrigante sobre los alemanes discriminados en la Colombia de los años 40, una novela que enseguida despertó la atención de la crítica colombiana. Está traducida a varias lenguas y dio fama mundial a su autor de 31 años en el año de su publicación.

La novela de Vásquez trata los sucesos ficticios acontecidos alrededor de la publicación, en 1988, de una biografía del periodista Gabriel Santoro sobre una amiga de la familia, Sara Guterman, una judía alemana llegada a Colombia en 1938, y la traición del padre del propio autor, también llamado Gabriel Santoro, informante en la época de las Listas Negras y artífice de la caída en desgracia de un hombre de origen alemán, Konrad Deresser. Como habremos de constatar, la novela nos permite asistir a un ir y venir entre un aquí y un allá que son a la vez Colombia y Alemania. Efectivamente, para salir de Alemania, el padre de la joven Sara compra «una fábrica de quesos en Duitama (una ciudad desconocida), Colombia (un país primitivo)» (Vásquez 2009: 31). La familia llega en un momento en el que los extranjeros no pueden integrarse fácilmente en su nuevo hogar, pues tienen prohibido ejercer un oficio diferente

\footnotetext{
${ }^{5}$ Cita procedente de Umberto Cobo: Geo von Lengerke, un bandido alemán en Zapatoca, en:

La Estafeta Literaria, Madrid, nº 625, 1977.
} 
al que desempeñaban en su patria de origen. Hay, incluso, una atmósfera antisemita, como se narra en el episodio donde se rechaza la contratación de siete taxistas judíos (cf. Vásquez 2009: 39-40).

Por presión de los Estados Unidos, el gobierno colombiano tiene que reducir las libertades de los ciudadanos del eje: italianos, alemanes y japoneses son excluidos de la sociedad colombiana y pierden sus privilegios. Más de cien ciudadanos de Alemania y de Japón son internados en el hotel Sabaneta en Fusagasugá. Se trata de un libro que mezcla personajes ficticios con hechos reales y acontecimientos inventados con personajes reales. El hilo conductor es el libro escrito por Gabriel Santoro (el periodista) sobre una amiga de la familia, la judía Sara Guterman, que llegó a Colombia en 1938 huyendo del nazismo. El libro habla de las Listas Negras, de las delaciones infundadas, que llevan a muchas familias al borde de un abismo. El texto de Juan Gabriel Vásquez muestra el lado oculto del ser humano, que denuncia a otros sin necesidad alguna.

Emil Prüfert y Hans Bethke, nazis mencionados en la novela, eran también en la realidad representantes nazis de alto nivel en Colombia en los años 30 del siglo pasado. Prüfert era el jefe de la sección colombiana del partido nazi en el exterior (NSDAP/AO) con sede en Barranquilla. Hans Bethke era un empresario nazi exitoso, que se mudó con su familia a Barranquilla y en la novela está presente en una cena en la casa de los Deresser, donde se queja de los excesos verbales de Konrad Deresser.

El encuentro entre judíos exiliados y comerciantes nazis en Colombia es también un reto presente en la novela del autor bogotano. Encuentros que eran inevitables en el exterior, sobre todo en América Latina, donde hubo siempre una fuerte inmigración alemana. El encuentro entre una judía, Sara Guterman, y el nazi convencido Hans Bethke se da en la casa de Konrad Deresser.

Eso es idealismo, y por eso le pareció necesario que yo fuera en representación de la familia a sentarme con un tipo del que se decía que tenía un retrato de Hitler en la sala. Aquí en Colombia es otra vida, aquí todos somos alemanes, decía, aquí no hay judíos ni arios, decía en el hotel, y en el hotel funcionaba. Sí hay que ser muy ingenuo, muy miope, ya sé. (Vásquez 2009: 157)

En la secuencia, el narrador describe el aspecto físico del nazi Hans Bethke, que, por una parte, corresponde a la imagen del nazi de apariencia impecable, pero por otra parte, no a la del ario, ya que tiene cabello muy diferente a los ideales de los nazis: «La cara de Hans Bethke, su afeitado perfecto y sus gafitas para ver de lejos, todo él te decía: yo te sonrío, pero no me des la espalda que te acuchillo. Tenía el pelo crespo y mono y engominado, y se le formaban espirales chiquitos en las sienes, toda su cabeza era un remolino...» (Vásquez 2009: 158-159).

Bethke es presentado en el texto literario como una persona peligrosa y sumamente astuta, como alguien que quiere tener ventajas a cualquier costo con 
las mudanzas políticas en la Alemania nacionalsocialista, un personaje siniestro y aprovechado, lleno de prejuicios.

\begin{abstract}
Algo se anuncia, Herr Deresser, está en el aire para quien quiera olerlo, y yo quiero se parte de eso, aquí en Colombia o en donde sea, da igual. Uno lleva su sangre a todas partes. No nadie renuncia a su propia sangre. ¿Por qué tendría un alemán que olvidarse de sí mismo al llegar aquí? ¿Ha olvidado usted quién es, lo han olvidado mis padres? Muy al contrario. Lo que pasó con sus hijos es otra cosa. ¿Sabe qué me parecen todos estos alemanes que no hablan alemán, con sus nombres en español y sus costumbres retrógradas, toda esta gente que llega tarde, porque aquí se llega tarde, que trabaja mal porque aquí son chapuceros, que miente y estafa, porque aquí eso es normal? Parecen enfermos. (Vásquez 2009: 160)
\end{abstract}

Como se puede percibir en la cita, Bethke representa al nacionalsocialista convencido, que abomina a las razas inferiores, ya que aquellas son impuntuales y no trabajan como los alemanes y tienen costumbres atrasadas, según él.

Los informantes no es solamente una novela sobre los alemanes en Colombia en aquella época, sino una historia que describe y analiza las razones que hunden al país en la violencia: la deslealtad está en primer lugar, aquí representada por la traición de Gabriel Santoro (padre) ante Konrad Deresser, acto que lo lleva a la reclusión en el famoso Hotel Sabaneta, transformado en campo de concentración para los ciudadanos del Eje en Fusagasugá. ${ }^{6}$

Para los libros de historia, la Segunda Guerra Mundial nunca llegó a Colombia, país que se consideraba neutro. La novela intenta recordar al lector que los conflictos son en principio personales y después se extienden a ser sociales y puede ser leída como un relato ficticio o como un informe literario de los años inmediatamente posteriores a la guerra; la escritura del texto induce al lector a ambas interpretaciones.

Es importante mencionar aquí la elaboración narrativa del mundo ficcional y su reconstrucción histórica con el propósito de analizar la manera en que el narrador-escritor reconstruye los hechos del pasado y reflexiona sobre los procesos de contar y narrar un relato. La parodia y la intertextualidad interfieren en la transgresión de la historia oficial para permitir la elaboración de una historia privada y personal sobre la migración de los alemanes a Colombia, sean ellos nazis o judíos durante e inmediatamente después de la Segunda Guerra Mundial.

El narrador le presenta al lector una síntesis de las consecuencias de las Listas Negras en Colombia, sin entrar en detalles históricos, relatando como se desarrolló la vida de Konrad Deresser después de la traición cometida por Santoro:

\footnotetext{
${ }^{6}$ La procedencia e índole de los reclusos alemanes en ese lugar fueron recientemente bien documentadas en una tesis doctoral en historia. Su autora cualifica Los informantes como un texto detectivesco con una construcción compleja que roza el género de la novela negra (Cardona González 2018: 26-27).
} 
Las listas duraron hasta un año después de terminada la guerra, y durante ese tiempo Konrad se cayó a pedacitos. Cuando se abolieron ya era tarde, ya el viejo era casi un mendigo, pero tampoco era el único. Hubo quienes sobrevivieron a las listas. Yo conocí a varios, algunos estuvieron en el Sabaneta, y de éstos algunos eran nazis de verdad. Otros ni siquiera llegaron a ser recluidos en el hotel, pero quebraron igual que quebró el viejo. (Vásquez 2009: 46)

El lector es informado por el narrador que Deresser, abandonado por su familia, sale de la reclusión completamente arruinado y termina su vida en Bogotá, donde vive con una prostituta y se suicida tomando unas pastillas en 1946 en una plaza pública, ya que había perdido su identidad, su familia, su trabajo y su hogar.

Otros alemanes o austriacos retratados en el libro son los dueños de la Librería Central, Hans y Lilly Ungar, cuya casa era el lugar de encuentro para los alemanes en Bogotá. La vida de los alemanes en los años 40 era marcada por el «Bloss nicht auffallen. [...] No hacerse notar. No llamar la atención» (Vásquez 2009: 319), ya que todos ellos eran sospechosos, así como los judíos que sufrían rechazo y exclusión en la Colombia de aquella época.

Con la superposición de distintos tiempos narrativos en el mismo libro, el narrador consigue que el destino de Deresser sea relacionado con la historia política colombiana de la siguiente forma:

Un año y medio después del suicidio de Konrad Deresser, el asesino de Gaitán fue metido a la fuerza a la droguería para evitar que la turba furiosa lo linchara, y de la droguería lo había sacado la turba furiosa, y lo había matado a golpes y lo había arrastrado desnudo hacia el palacio del presidente. (Vásquez 2004: 247-248)

El autor vincula la historia de las Listas Negras con el Bogotazo para subrayar la importancia del modelo dominante de la política de entonces: la violencia. Durante la época de las amenazas nazis es cuando también comienza la sumersión a los intereses de los Estados Unidos. Vásquez muestra como personas inocentes pueden ser denunciadas y castigadas sin ninguna culpa comprobada.

Colombia como país de inmigración no pudo liberarse de la presión de los EE. UU., que tenía como objetivo principal la eliminación de un rival económico poderoso en el área de su influencia: Alemania.

\section{EL PIANISTA QUE LlEGó DE HAMBURGO}

El pianista que llegó de Hamburgo (2012) de Jorge Eliécer Pardo es otra novela que intenta tejer una vinculación entre la inmigración alemana y la historia de Colombia durante la Segunda Guerra Mundial y la llamada época de la violencia.

El libro está repleto de contradicciones, errores, datos inciertos o tergiversados. Prácticamente todos los nombres propios alemanes y extranjeros 
contienen errores, así como los hechos históricos que no fueron realmente analizados para la composición de la novela. Un joven judío no estaba obligado a hacer el servicio militar y mucho menos a los 15 o 16 años como describe el libro. Hay otras negligencias del autor, pero nos vamos a dedicar al análisis del contenido de la novela.

Se trata de la historia de un joven judío, Hendrik Pfalzgraf, que huye con su tío Azriel de la persecución nazi a Colombia y llega a Barranquilla, donde encuentra trabajo en las fábricas Pfaff (máquinas de coser, que serían justamente de Emil Prüfert, jefe de la NSDAP-AO, organización del partido nazi en el exterior).

El lapso de tiempo narrado es de 65 años, entre 1920 y 1985. La historia se cuenta desde la voz de un narrador heterodiegético (Alfonso 2015: 31) y comienza con las graves consecuencias de los primeros años de Hitler y su partido Nacionalsocialista en el poder para el protagonista Hendrik. La vida del exiliado judío Hendrik también se ve marcada por dolor y sangre en su nueva patria, una Colombia impregnada de la xenofobia y la persecución estadounidense impuesta en toda América Latina. Son varios los sucesos históricos colombianos recreados en la novela, como El Bogotazo, presenciado por Hendrik, lo que produjo repercusiones directas en su familia:

Mientras escuchaban las noticias a bajo volumen no podían creer que la guerra siguiera persiguiéndolos. La niña estaba cansada y a las dos horas se durmió. No hablaron hasta el amanecer cuando el aguacero amainó. (Pardo 2012: pos. 403)

Esa angustia se presenta como uno de los momentos más importantes de la novela con relación a la actualidad política de la Colombia de los años cuarenta. Hendrik puede comprobar que la sangre no sólo correría en Europa sino también en el Nuevo Mundo, ya que el día que asesinaron a Jorge Eliecer Gaitán, Bogotá quedó muy destruida y con más de 3000 muertes. Los actos de violencia descontrolados hacen recordar a Hendrik la violencia y el odio sufridos en Alemania. Hendrik es un exiliado alemán que vive de primera mano los enfrentamientos bélicos y la precariedad de Colombia.

La división existente entre liberales y conservadores desvela, ya que Hendrik se encuentra con un pueblo violento y rencoroso en su país de acogida, viéndose sumergido en el abandono, la pobreza y la tristeza de una guerra continua, que es el periodo conocido como La Violencia. Estas experiencias se entrelazan en un tono depresivo y melancólico en el texto, una continuación de los actos violentos sucedidos en Europa.

Igual que en la novela de Juan Gabriel Vásquez, el autor menciona el impacto de las Listas Negras en la vida cotidiana de la gente con apellido alemán. Se trata de una respuesta de los Estados Unidos contra cualquier iniciativa política o económica de alemanes en Colombia.

La novela destaca la posición protagónica de Barranquilla en la afluencia de los inmigrantes. Fue un punto importante para la llegada y partida de 
extranjeros en los años 40 del siglo pasado. El autor sitúa su historia en este lugar para mostrar la xenofobia que inundaba a los dirigentes políticos de Colombia y la discriminación racial que sufrían los judíos y revela a Luis López de Mesa como un antisemita a causa de sus convicciones políticas y su proximidad a la política estadounidense:

\begin{abstract}
Azriel y Hendrik seguían en Barranquilla a pesar del canciller Luis López de Mesa quien escribió en una circular que el gobierno consideraba a los cinco mil judíos establecidos un porcentaje insuperable. Pedía a los cónsules que pusieran las trabas posibles al visado de nuevos pasaportes para impedir el ingreso de judíos, rumanos, polacos, checos, búlgaros, rusos, italianos. [...] Hacia énfasis en que los judíos que abandonaban Alemania perdían su identidad, adquirían la condición de apátridas y que para dejar de serlo solicitaban la nacionalidad. (Pardo 2012: pos. 258-261)
\end{abstract}

Mientras tanto, el mismo canciller Luis Lopéz de Mesa describía a los alemanes no judíos en Colombia como «disciplinados, laboriosos y patriotas» (Pardo 2012: pos. 273) y sobre los judíos afirma que «tenían una orientación parasitaria de la vida» (Pardo 2012: pos. 265). Por lo tanto, Hendrik y su tío Azriel sufren una doble persecución, por ser judíos y por ser acusados o sospechosos de ser simpatizantes del nazismo, no obstante, de su condición de exiliados. El narrador relaciona y compara la muerte en los campos de concentración con los bombardeos de Hamburgo y con la persecución sufrida en Colombia: «Azriel y Hendrik se dieron cuenta de que eran perseguidos en todas partes y que en su país exterminaban a sus familiares en la esclavitud muerte natural - o con los gases Ziclón B, en las duchas» (Pardo 2012: pos. 301). La situación se agrava todavía más con la noticia de la muerta de la esposa de Azriel y de sus hijos a causa de los bombardeos intensos de los aliados a Hamburgo en julio/agosto 1943 . $^{7}$

Hendrik representa el judío errante, quien vive en la tierra en función de cuidar su vida de los enemigos (Alfonso 2015: 37), ya que se había escondido durante cinco años en Alemania para no ser reclutado para el servicio militar. Se ve decepcionado y defraudado, una vez que había asociado la vida en Colombia con bienestar y tranquilidad, pero esta esperanza de tener una vida en paz y libertad desvanecía. Además de ser judío era alemán y, por lo tanta, su destino era el Hotel Sabaneta, lugar de reclusión para los alemanes señalados con supuestos vínculos estrechos con el partido de los nazis.

El día 23 de marzo de 1944 el gobierno de Colombia mandó arrestar a los súbditos del Eje por considerarlos «peligrosos y subversivos» (Pardo 2012: pos. 311). Aunque el rigor de las Listas Negras no es el mismo expuesto en la novela Los informantes, para Hendrik el hecho de figurar en las listas significaba un aumento de su dolor, de su sufrimiento y la intensificación de la mala suerte que se manifiesta. Es oriundo de una familia con pocos recursos económicos, un

\footnotetext{
7 El autor menciona aquí 50.000 muertos, pero en realidad murieron 34.000 personas en la operación Gomorrha, según cálculos actualizados por los historiadores.
} 
emigrante pobre y se transforma en un esclavo, un prisionero de sus angustias y de su pasado, como podemos observar en los recuerdos, que tiene de su hija y de su esposa:

Mi hija Laura, se diluye en la neblina espesa. Se la llevan unos hombres indefinidos, con uniformes de casacas y gabanes grises que, entre el claroscuro dan la espalda. Detrás de la cortina densa están los niños de Lebensborn, en el castillo donde crecen los hijos de Hitler, los pequeños engendrados por soldados nazis, rubios, de ojos azules y de más de un metro con setenta de estatura. Laura camina hacia el bosque, voltea la cabeza y me mira, como suplicando el rescate, en este solsticio de invierno. Como miles de niños de Polonia, Checoslovaquia y Francia, es secuestrada para que forme parte da la guardia pretoriana del Führer. (Pardo 2012: pos. 1555-1561)

El lector puede observar unas conexiones y relaciones absurdas, fuera de la realidad: ¿Cómo la hija de un judío emigrado a Colombia puede ser secuestrada para la procreación de nuevos arios en un Lebensborn, institución que servía para la manutención de una raza pura? En el mismo capítulo continúa la imaginación fantástica y utópica del narrador, relacionando el destino de su hija con insignias nazis y el famoso castillo Wewelsburg de las SS:

Entregan a mi niña el anillo con la calavera como símbolo y lealtad al Führer: obediencia, fraternidad y camaradería. La cabeza de la muerte que recordará a Laura que se halla lista para sacrificar su existencia en cualquier momento, por el bien de la raza germánica. La insignia la sacan del santuario secreto, del castillo de Himmler, en Wewelsburg, herencia de uno de los oficiales de la vieja guardia, muerto en combate. (Pardo 2012: pos. 1569)

Lo surreal es un factor permanente en la obra de Jorge Eliécer Pardo, como se puede comprobar constantemente. El autor da rienda suelta, en lo que se refiere a su fantasía en el siguiente trecho en varios otros:

[...] mis pesadillas empezaron cuando Magdalena se marchó. Hitler, mi eterno enemigo, se apodera de mi cuerpo y me hace ver la terrible realidad de mi vida. Odio a Hitler y, aunque sé que está muerto, su imagen me avasalla hasta hacerme saltar de la cama. Yo también temo a las mujeres y hablo con desprecio de los artistas falderos.

[...] estoy en la mesa, con Eva Braun presidiendo el té, después en fuga con ella, manejo su Mercedes Benz a más de ochenta kilómetros por hora, despreocupado, tomando las curvas sin pisar el freno. Otra noche volamos un pequeño avión y en lo más alto fornicamos y luego Eva me lanza al vacío. (Pardo 2012: pos. 529-535)

En la novela de Pardo, las pesadillas del protagonista Hendrik desempeñan un papel importante, ya que ellas demuestran un estancamiento en la mente y en las ideas del personaje a causa del trauma vivido en Alemania y de la pérdida de familiares según Alfonso (2015: 40).

La comparación entre Almudena Grandes y Jorge Eliécer Pardo, en lo que se refiere al retrato de los hechos de Segunda Guerra Mundial, no parece de las más adecuadas, ya que la autora madrileña siempre se deja guiar por la verosimilitud y el autor tolimense por la fantasía y lo absolutamente 
inverosímil. ${ }^{8}$ Jorge Eliécer no se muestra preocupado con la cuestión de la semejanza del texto literario a una realidad, que marcó el transcurso de la historia del país y del mundo, el autor quiere apenas fabular.

\section{Al OTRO LADO DEL MAR}

La autora colombiana María Cristina Restrepo publicó en 2017 un libro muy bien construido e impactante, que trata de los diferentes tipos de migraciones de Alemania a Colombia y al revés en los años 30 y 40 del siglo pasado. La relación entre Colombia y Alemania en el siglo XX está retratada a través de un conjunto de personajes pertenecientes al comercio y a la diplomacia que se ven confrontados con las deportaciones provocadas por la guerra entre el Tercer Reich y los Aliados. Las consecuencias de las llamadas Listas Negras, es lo que caracteriza esta novela: alemanes, que no se consideran nazis, son expulsados por el gobierno de Eduardo Santos bajo las exigencias de los Estados Unidos. Alemanes que, desde el caos, el hambre, el frío y la guerra en Europa añoran la luz, la concordia, los sabores y los olores y la gente cordial de un país llamado Colombia. Resulta paradigmático, por no decir conmovedor, que un país como Colombia, durante la segunda mitad del siglo XX símbolo de la violencia, sea evocado por estos alemanes desamparados como el único lugar donde es posible salvarse de persecuciones y vivir en paz.

Los alemanes en la obra de María Cristina Restrepo no son personajes comunes y corrientes, ya que poseen esa singularidad propia de los personajes inolvidables. Albert, Honorine y sus hijas Gudrun y Elisa, las madres y abuelas, el doctor Fischer, Wolfgang y su madre Klara, impresionan al lector. El carácter de los alemanes tiene que ver, en buena medida, con el vínculo que tienen con Colombia, hecho que los definiría como seres humanos raros, exóticos, híbridos y distantes de las nociones de pureza que tanto han caracterizado al nacionalsocialismo. María Cristina Restrepo se ha amparado, para efectuar estas conmovedoras pesquisas del pasado histórico, en el destino de las mujeres. Se trata de una novela, en la cual el dolor y la crueldad de la guerra están siendo contados, sobre todo, desde el sufrimiento de los personajes femeninos. El sufrimiento se transforma en resistencia a una práctica esencialmente masculina como es la guerra. Observamos una resistencia que parte siempre desde la preservación de las cosas simples y de la vida.

Muchos de los emigrantes alemanes residentes en Colombia manifiestan su rotundo rechazo a la ideología nazi, cuando perciben los cambios radicales acontecidos en Alemania después de las leyes de Nurémberg en 1935 de carácter racista y especialmente después de la Noche de los Cristales rotos en noviembre de 1938:

\footnotetext{
8 Véase la reseña en el periódico El tiempo del 4 de junio de 2012, https://www.eltiempo.com/archivo/documento/CMS-11922621.
} 
Las cosas no son así de sencillas. ¡Nada de lo que ocurre en Alemania lo es! No me gusta el giro que toma la política, ni el poder del NSDAP, ni la propaganda nazi, ni la invasión a Renania. ¡Nada de eso me inspira confianza! Tenemos que rechazar la discriminación a la que someten a los judíos. (Restrepo 2017: pos. 490)

Más tarde, con el inicio de la Segunda Guerra Mundial, los alemanes en Colombia empiezan a sufrir diversos tipos de discriminaciones y se plantean la cuestión, cuál sería el gobierno más nocivo a sus intereses, el de la Alemania nazi o de los Estados Unidos, cual es el régimen que amenaza más su tranquilidad. Honorine, la protagonista de la novela, sentía rabia, impotencia y temor ante la velada amenaza por parte del gobierno colombiano.

Corre con fuerza aquel rumor de que, en consenso con las organizaciones comerciales, diplomáticas o consulares, existe una organización política nazi bajo la dirección de Emil Prüfert, en Barranquilla, apoyada por un grupo de simpatizantes colombianos, japoneses e italianos, dedicados a la encubierta propaganda del Eje. (Restrepo 2017: pos. 1145)

El rechazo a las medidas tomadas por el gobierno Eduardo Santos fue muy grande y los alemanes se sintieron engañados y perjudicados, ya que habían sido víctimas u opositores a los nazis o eran al menos indiferentes a su política.

Los sufrimientos y trastornos sufridos por los alemanes de las familias en Colombia no terminan con la expropiación de sus bienes en Colombia y su expulsión a la Alemania nazi con escala en los Estados Unidos. En Alemania les espera la desconfianza y la vigilancia de la Gestapo. El país se encuentra en plena guerra y el régimen nazi desconfía de todos que vienen del exterior. En esta situación, la familia Arper llega a Alemania sin poder integrarse y sin empleo.

También Restrepo inserta en su novela el episodio de los últimos días de los nazis en el bunker de la Neue Reichskanzlei en Berlín, con la muerte de Adolf Hitler, Eva Braun, de sus seguidores más próximos y de la familia del ministro de propaganda Joseph Goebbels.

El 1. ${ }^{\circ}$ de mayo, los seis niños a quienes su madre, con el rostro mortalmente pálido, había ayudado a preparar para ir al lecho, se disponían a irse a la cama. Sin que lo supieran les habían suministrado un poderoso calmante. Debían morir, pues sus padres consideraban que no habría lugar para ellos en Alemania, donde los mirarían con odio y desprecio. Apenas perdieron la conciencia les introdujeron en la boca cápsulas de cianuro, apretándoles las mandíbulas para partirlas con las muelas. Helga, la mayor, se debatió contra las manos que le arrancaban la vida. (Restrepo 2017: pos. 2900-2904)

La caída de los nazis más destacados en Berlín ha sido tema de numerosos libros de ficción ${ }^{9}$ y dio origen al mito de un Hitler sobreviviente y refugiado en

\footnotetext{
${ }^{9}$ También la muerte de los hijos de Goebbels ha sido retratada en diversas obras literarias, la más destacada es sin duda: Flughunde (1995) de Marcel Beyer, traducido al castellano por Georg Pichler como El técnico del sonido (1999).
} 
Latinoamérica. La autora contrasta el destino de los altos jerarcas nazis con los sufrimientos de la población civil en Berlín al final de la guerra, que padece las consecuencias de la derrota y de la batalla final en la capital alemana. Entre estos alemanes también se encuentra la familia expulsada de Colombia en el año 1941 a consecuencia de la presión estadounidense. De esta forma hacen un recorrido inverso al de los emigrantes judíos refugiados en Colombia, figuras en las dos novelas anteriores. Al final no pueden evitar la violencia de los soldados rusos contra las mujeres alemanes y son víctimas de una actuación, que era muy frecuente en el caos de las horas finales de guerra y se transformó también en un tópico de narrativas. Al final, vayan por donde vayan los protagonistas de la novela, son alcanzados por una feroz violencia.

Gudrun, Klara y Emil se preparaban para bajar al sótano de la estación del U-Bahn. Los vecinos esperaban que unidos pudieran enfrentar a los rusos, haciéndolos desistir de cualquier intención violenta. Dos pensamientos ocupaban la mente: procurarse agua y comida, en especial para los niños, y escapar de la legendaria ferocidad de los atacantes $[\ldots]$

Klara cayó de espaldas en el piso de cemento. Parecía haber perdido la conciencia, pero al cabo de unos segundos abrió los ojos para ver a su madre, víctima de otro soldado que la abofeteaba, arrojándola al suelo. Se esforzó por no reaccionar al ultraje. Cinco soldados la violaron antes de perder la conciencia, hundiéndose en un espacio nebuloso del que no habría querido regresar. (Restrepo 2017: pos. 2924-2962)

\section{DIARIO DEL FIN DEL MUNDO}

El libro más reciente de los abarcados aquí en este breve análisis es la última novela de Mario Mendoza con el título Diario del fin del mundo, publicado en 2018 poco después del libro de Abel Basti: Hitler en Colombia. Podemos sospechar que el autor bogotano se quería aprovechar un poco del auge del tema del nazismo y de los nazis escondidos en Colombia.

En Diario del fin del mundo, el alemán Karl Klein es uno de los médicos de la SS huidos a tierras suramericanas. Camuflado gracias a la numerosa presencia de empresas alemanas en Colombia, durante aquellos años del final de la II Guerra Mundial, Klein logró burlar a las autoridades y llevar una vida sosegada en Bogotá. Tuvo un matrimonio por conveniencia, del cual nació Daniel amigo del narrador Mario Mendoza. La madre de Daniel desaparece misteriosamente y éste cree que ha sido Klein quien la ha asesinado. Comienza a seguir a su padre y descubre su oscuro pasado, por lo que decide encontrar cobijo en la guerrilla para, más tarde, huir del país.

Klein va a ser parte de las estructuras silenciosas de represión y muerte que forman parte de la realidad colombiana. La violencia, la sevicia y el poco valor que tiene la vida humana en la sociedad colombiana, oscuridades promovidas desde altas esferas políticas, van a ser el camuflaje perfecto para un psicópata como Klein. El brote de violencia interminable que padece la realidad 
colombiana será un estímulo más del fin del mundo que se anuncia al final de la novela. Un atroz epílogo que, acorde con el universo narrativo de Mendoza, no es sino un vaso comunicante más de la cultura del odio y la mentira que se apodera del mundo actualmente: racismo, misoginia y el sentirse orgulloso de la ignorancia, banderas que apuntalan la hecatombe que se aproxima de la mano del resurgimiento del fascismo, a través de partidos políticos de ideologías extremas y caudillos, promotores de la calumnia y el odio, sujetos que avalan el resurgimiento de la figura de Hitler a través del culto a la personalidad y el fanatismo.

Karl Klein es el nombre adoptado por Klaus Zimmermann, un ficticio ayudante de Joseph Mengele en el campo de exterminio de Auschwitz. Sobre este personaje podemos leer en la novela y su fuga inventada está descrita de la siguiente forma:

Le consiguió un pasaporte falso a nombre de Karl Klein, una buena suma de dinero para viajar a América Latina y rehacer su vida, lo envió a Colombia (inicialmente a Barranquilla) como lo hubiera podido enviar a Lima o a Caracas, y él bajo el apellido de Gregor, se refugió en Argentina. (Mendoza 2018: 171-172)

Mendoza también levanta la hipótesis de una muerte de Hitler inventada, ya que tenía varios dobles para su protección. Uno de ellos, Ferdinand Beisel, fue escogido para quedarse en el bunker hasta los últimos días de abril en 1945. Según Mendoza el doble cumplió

con un guion establecido mientras el Führer escapaba de las tropas soviéticas, que ya estaban entrando a Berlín. Después cruzó países aliados, como España, hasta que logró abordar un submarino que lo estaba esperando para conducirlo al fin del mundo. Este era un plan que se había elaborado con sumo cuidado para sacar el jefe supremo en caso de perder la guerra. (Mendoza 2018: 185-186)

Mario Mendoza cita como fuente a Abel Basti, mundialmente conocida por sus dudosas teorías sobre una supuesta permanencia de Hitler en Argentina después de 1945, que se vendieron muy bien en Argentina y en otros países de América Latina.

El autor/narrador establece conexiones con Erik Hanussen, el ocultista de Hitler, también objeto de varias novelas en lengua española, describiendo su importancia de la siguiente forma: « [...] Hitler al comienzo de su carrera estuvo asesorado por un nigromante, por un mago y mentalista que lo aconsejó en todos sus movimientos militares, Erik Hanussen». ${ }^{10}$ Hanussen realmente es un personaje histórico, pero fue asesinado por la SA ya en marzo de 1933, pocos días después de la llegada de los nazis al poder y, por lo tanto, nunca asesoró a Hitler en cuestiones militares.

\footnotetext{
${ }^{10}$ La figura de Hanussen también aparece en dos novelas latinoamericanas recientes como protagonista: El mentalista de Hitler (2016) del uruguayo Gervasio Posadas y El legado (2017) de la peruana Blanca Miosi.
} 
Mendoza también relaciona a los nazis con el asesinato de Jorge Eliécer Gaitán: La calavera en el anillo del supuesto asesino Roa Sierra sería idéntica a aquella utilizada en rituales nazis clandestinos en un lago cerca de Sogamoso. Finalmente, el autor pretende comprobar la implicación nazi en el famoso asesinato, que desencadenó el Bogotazo de la siguiente forma. La conexión de Roa Sierra con el mundo nazi estaría comprobada de la siguiente manera, según Mendoza:

El hermano mayor de él era conductor de la embajada alemana en Bogotá. Roa entró como portero del edificio en 1941, un momento de auge para Alemania dentro de la guerra [...] Roa Sierra también entabló contacto con un mago alemán llamado Johann Umland. Él lo introduce en el esoterismo rosacruz y le habla de la transmigración de las almas, del karma, de la energía vril. [...] Umland es el maestro que lo inicia en los misterios del ocultismo nazi. Por eso seguramente llevaba ese anillo y eso significa que fue reclutado por la sociedad Thule. El siguiente paso fue conducirlo a matar a Gaitán. (Mendoza 2018: 199-200)

El mismo Johann Umland que también aparece como personaje destacado en la novela de Miguel Torres: El crimen del siglo, que trata con todos los pormenores la historia del Bogotazo, sin mencionar algún vínculo entre Umland y los nazis.

Existen innumerables teorías sobre el asesinato de Gaitán, pero ninguna indica una responsabilidad directa de los nazis, ya que la Segunda Guerra Mundial había terminado tres años antes y los fugitivos tenían que esconderse y no poseían muchas posibilidades para planear atentados.

De esta forma Mario Mendoza se coloca en el lugar del narrador de la historia más absurda y fantástica, que intenta escribir textos ficcionales sobre el tema de la presencia de los nazis en Colombia. Nada o casi nada de lo que expone en su última novela es verdad o verosímil, ni presenta alguna semejanza con hechos históricamente comprobados.

\section{CONCLUSIONES}

La lectura de cinco novelas de la literatura colombiana ha demostrado cuáles son las imágenes del alemán existentes y dominantes en la literatura actual de Colombia. Con el análisis de los textos citados arriba se ha mostrado que la imagen del alemán es variopinta y diferente de una novela a otra. Las novelas con bases en estudios más profundos y con una descripción más pormenorizada son también las obras de mayor calidad literaria.

En este momento falta añadir que hay otras obras importantes y relevantes para el tema de la investigación que no podían ser analizadas en este artículo: Deborah Kruel de Ramón Illán Bacca (1981), El verso de Kaplan de Marco Schwartz (2006), las novelas de William Ospina, sobre todo Úrsua (2006) o El as de 
corazones (2017) de Héctor Moreno, como también la famosa novela de Alfonso López Michelsen: Los elegidos (1953).

La actuación de los alemanes en Colombia fue importante para el desarrollo y la industrialización del país, pero hay que destacar una cierta soberbia en su conducta frente a la población nativa. Vale la pena mencionar el momento crítico de las Listas Negras, cuando muchos alemanes cayeron en desgracia y fueron internados o expulsos, aunque eran inocentes y no apoyaban al régimen nazi. Es intrigante que muchos judíos, que se habían refugiado a Colombia, confiando que estaban a salvo en el Nuevo Mundo, fueron perseguidos y sufrieron una nueva discriminación por causa de su religión.

Hubo un cierto auge de la emigración después de la Primera Guerra Mundial, que tuvo su repercusión en los avances tecnológicos en el transporte fluvial, marítimo y aéreo, en la creación de bancos y casas comerciales. Estos hechos influenciaron en la representación del alemán en la literatura, aunque hubo más tarde una sobreposición de la imagen del nazi en algunas obras literarias.

Los alemanes como figuras literarias están muy presentes en la literatura contemporánea colombiana, como se pudo comprobar con este trabajo. Su espíritu conquistador, pionero, emprendedor y aventurero marcó la historia de Colombia desde el siglo XVI hasta la actualidad. Al contrario de lo que ocurre en otros países suramericanos, no son los nazis fugitivos los personajes recurrentes, sino los ciudadanos alemanes que habían llegado antes del auge del nazismo y fueron discriminados a partir de 1941, cuando Colombia se tenía que alinear con su política directamente con los Estados Unidos y en contra de los países del Eje.

Todavía existen teorías difusas, acusando a los alemanes de tener escondido a Adolf Hitler en suelo colombiano. Este auge de temas relacionados a los nazis en la novela actual merece una atención especial para descubrir las intenciones de las historias fantásticas y analizar sus trasfondos, sean ellos más auténticos o más ficcionales. Sobre la funcionalidad de una presencia de figuras nazis en la literatura colombiana actual se pueden hacer diversas especulaciones, pero el tema de la sumisión de la nación colombiana a los intereses de las dos potencias más poderosas en aquella época: Alemania y Estados Unidos, constituye el eje temático central de diversas novelas.

Para resumir el análisis, se puede decir que las novelas con falta de exactitud de sus investigaciones históricas también son las obras menos elaboradas en lo que refiere a la calidad literaria y con una enorme falta de verosimilitud.

La época de las Listas Negras no fue solamente decisiva para el destino de los alemanes residentes en Colombia, sino para el país entero, ya que significaba un alineamiento mayor con la política de los Estados Unidos que aún no había encontrado su fin. Analizando las distintas obras literarias con la temática enfocada en esta cuestión, podemos percibir una cierta simpatía o 
comprensión por parte de los autores con la situación de los ciudadanos del Eje en Colombia, ya que una buena parte de inmigración alemana existía muchas décadas antes de la llegada del nacionalsocialismo. Banqueros, comerciantes, aviadores, aventureros e ingenieros procedentes de Alemania contribuyeron al desarrollo de las diversas partes del país andino y dejaron sus huellas de una forma indeleble en la historia de Colombia.

El bicentenario de la independencia de Colombia, que se conmemora en 2019, es un motivo también para reconsiderar algunos episodios de su historia y el papel de alemanes, norteamericanos y otros extranjeros en este proceso. ${ }^{11}$

\section{BIBLIOGRAFÍA}

ALFONSO, C. C. (2015), «Todo tiempo pasado fue peor: La representación literaria del nazismo en Vásquez, Pardo, Borges y Bayer», Graduate Theses and Dissertations, Florida, University of South Florida. Disponible en: $<$ https://scholarcommons.usf.edu/etd/5896>.

CARDONA GONZÁLEZ, L. (2018), Una colectividad honorablemente sospechosa: Los alemanes, Colombia y la Segunda Guerra Mundial, tesis de posgrado, La Plata, Universidad Nacional de La Plata, Facultad de Humanidades y Ciencias de la Educación. Disponible en: <http://www.memoria.fahce.unlp.edu.ar/tesis/te.1616/te.1616.pdf>.

Gómez VALDERRAMA, P. (1986), La otra raya del tigre (1977), Madrid, Editorial alianza.

HoudE, C. (2017), «Una geografía de la memoria en Los informantes de Juan Gabriel Vásquez y El mundo de afuera de Jorge Franco», Estudios de Literatura Colombiana, 40, Universidad de Antioquia, 13-27. Disponible en: $<$ https://aprendeenlinea.udea.edu.co/revistas/index.php/elc/article/view/326552>.

LÁZARO, J. A. (2012), «Presencia extranjera en Barranquilla: el caso de los alemanes, sus actividades económicas y el final de su influencia en la urbe caribeña 1930-1941» en MEMORIAS Revista digital de Historia y Arqueología desde el Caribe colombiano, 9(16), 165-197. Disponible en: <http://rcientificas.uninorte.edu.co/index.php/ memorias/article/viewArticle/3258>.

LÁZARO, J. A. (2016), Extranjeros en el Caribe colombiano: el caso de los alemanes en Barranquilla, 1919-1945. Migración, dinámicas de grupo y política internacional, tesis doctoral, Sevilla, Universidad Pablo de Olavide. Disponible en: $<$ https://www.educacion.gob.es/teseo/imprimirFicheroTesis.do?idFichero=dyP9T $\% 2 \mathrm{~B} 5 \mathrm{Yy} 0 \mathrm{~A} \% 3 \mathrm{D}>$.

MAHLENDORFF, A. (2000), Literarische Geographie Lateinamerikas. Zur Entwicklung des Raumbewußtseins in der lateinamerikanischen Literatur, Berlin, Edition TranvíaWalter Frey.

PARDO, J. E. (2012), El pianista que llegó de Hamburgo [libro electrónico], Bogotá, Cangrejo Editores.

\footnotetext{
${ }_{11}$ Agradezco al profesor y escritor Alberto Bejarano del Instituto Caro y Cuervo por las conversaciones muy estimulantes sobre la literatura colombiana contemporánea y, sobre todo, por la revisión del presente texto.
} 
PÉREZ GUTIERREZ, J. M. (2014), La autoconciencia narrativa y el discurso ficticio en Los informantes de Juan Gabriel Vásquez, tesis de maestría, Bogotá, Universidad de los Andes, Disponible en: <https://repositorio.uniandes.edu.co/bitstream/ handle/1992/13130/u714161.pdf?sequence=1\&isAllowed=y $>$.

RESTREPO, M. C. (2017), Al otro lado del mar [libro electrónico], Bogotá, Alfaguara.

VÁsQueZ, J. G. (2004), Los informantes (2004), Bogotá, Punto de Lectura.

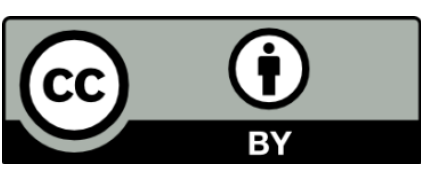

Los textos publicados en esta revista están sujetos - si no se indica lo contrario - a una licencia de Reconocimiento 3.0 España de Creative Commons. Puede compartirlos con terceros siempre que reconozca su autoría, la publicación inicial en esta revista y las condiciones de la licencia. 